\title{
Methodology for assessment and risk management of the investment and construction project
}

\author{
Elena Nidziy* \\ Moscow State University of Civil Engineering, Yaroslavskoe shosse, 26, Moscow, 129337, Russia
}

\begin{abstract}
The purpose of this work is to substantiate and develop methods of analysis, accounting and assessment of risks in investment and construction activities as a factor of successful implementation of the investment project. Improving the efficiency of the investment and construction project implementation can be ensured by the use of adequate methods for identifying, analyzing, evaluating, forecasting and preventing risks during the project implementation. The author developed a comprehensive methodology for risk analysis and assessment during the implementation of an investment and construction project taking into account the peculiarities of the industry in order to improve the risk management mechanism. The practical significance of the article lies in the possibility of using the developed integrated methodology for analyzing and assessing the risks of an investment and construction project as a mandatory condition for the safe functioning and development of investment and construction activities in the implementation of projects.
\end{abstract}

\section{Introduction}

Investment and construction activities are inevitably affected by various risks in one aspect or another. Therefore, whenever financial analysts and risk specialists have several options, each of which, on the one hand, reduces some types of risks, and on the other, involves certain expenses, losses and threats, they deal with a compromise between the benefits of eliminating risks and the costs that will have to be incurred to reduce these risks.

The problem of the theoretical and methodological justification of the risk management methodology of projects related to residential real estate includes the solution of issues of investment and project management. There is no unified comprehensive methodology for managing the risks of residential real estate investment projects in the practice of project management. In view of the above, the choice of risk management methods, their analysis and assessment, as well as the classification of project risks are now very relevant scientifically.

The reliability of the analysis, accounting, assessment and prevention of risks during the implementation of the investment and construction project led to the goal of the study.

\footnotetext{
* Corresponding author: elena.nidziy@mail.ru
} 
Questions of the analysis and assessment of investment projects with statement of the main economic and administrative aspects are in detail considered by such scientists as Yu.Ya. Eleneva, V.V. Kovalyov, V.N. Livshits, I.V. Lipsits, S.N. Maximov, I.I. Masur, N.G. Olderogge, M.L. Rasu, Smolyak S.A., E.I. Tarasevich, V.D. Shapiro, etc. [1-4] Of the foreign authors who paid attention to this issue, the following scientists can be named: $G$. Behrens, M. Weiss, M. Miles, R. Peiser, A. Frey[5].

To date, it is advisable to talk about the existence of a wide range of methods recognized by society that allow assessing the risks of projects, including investment and construction. Of particular note is the method of expert assessments developed by $\mathrm{O}$. Helmer in the United States in the fifties of the twentieth century[6]. The effectiveness of applying the prevailing part of the methodologies used is undeniable, however, they need special development and material plan costs that can compensate for the range of benefits from their use. Therefore, it is necessary to have a clear understanding of the expectations of the risk assessment procedure and the way in which the technology is integrated into the process of managing the investment and construction project.

\section{Methods}

Assessing how effective an investment and construction project is, it is necessary to take into account the probability of the appearance and implementation of various kinds of risks that are directly related to activities carried out in the construction business segment. The implementation of risk management activities makes it possible for the enterprise to minimize possible losses in case of risk circumstances, which helps to increase the efficiency of investment injections into the developed project [7].

In terms of risk management in an investment and construction project, as it is implemented, we are talking about a repetitive sequence of steps throughout life, designed to make the investment construction project sustainable, despite the consequences that have negative situations [8-11].

In the context of developing a risk management plan, two stages should be identified. At the first stage, risks are assessed using various methods; in the second stage, direct management is carried out in relation to the identified risks in the process of their assessment.

Let us dwell in detail on each of the phases.

I. Evaluation phase. Risk assessment involves procedures such as qualitative and quantitative analysis. It is necessary to analyze risks in order to obtain fair estimates of how effective an investment project is, as well as to increase the validity of the decision made in accordance with the draft $[12,13]$.

Giving an interpretation of the mechanism designed to assess the risks of the investment and construction plan, in fact, we are talking about methods and forms that collectively allow us to assess risks. Among the main components of this mechanism, it is advisable to distinguish: the system, goals, functions, tasks, principles, methods used in assessing such a category as risks.

In assessing investment and construction risks, it is necessary to indicate the following: the influence exerted by the management system (the entity implementing management) - a construction company, guided by the principles that exist in objectivity, is subjected to a controlled system (this is a managed object), which is carried out in order to implement the goal, minimizing the total risk during the implementation of the investment and construction project [14].

When studying the concepts of risk assessment of an investment and construction project, they often use comparative analysis as a research basis. Such a technique is the simplest and most effective of the existing ones. 
Speaking about the method that allows assessing risks in the project of the investment and construction order, in fact, we are talking about a reception or a system that includes techniques through which individual operations are carried out in the management implemented in relation to risks. This means that, by applying risk assessment techniques, it is possible to address the key challenges of identifying possible adverse scenarios, assessing the likelihood of their implementation and the extent of the possible consequences that will result. The complexity of the tasks is due to the fact that today there are countless methodologies that allow assessing risks.

In modern conditions, the techniques presented by the software simultaneously coexist with easy-to-use, publicly available methods that allow assessing risks.

In interpreting the algorithm by which risks are assessed, it is advisable to talk about a certain exact sequence of steps designed to convert data related to possible negative situations and consequences into events presented in the complex, which can reduce the degree of influence exerted by risks, which, in turn, will make it possible to increase the probability of successful implementation of the project.

In our opinion, in terms of the algorithm inherent in the mechanism that allows assessing risks as the project of the investment and construction plan is implemented, it is advisable to distinguish sequential operations, consisting in [15]:

1) identify;

2) analyze;

3) evaluate;

4) implement a set of measures to reduce these risks and determine how effective the process was.

II. The phase interfaced to management. The maintenance of control exercised in relation to risk is in developing and carrying out the optimum events and recommendations having the economic justification and directed to reduction of initial level, leading him to acceptable total level. Implementation of management concerning risks demands to consider the received results reported by assessment applied to risks, the analysis which was undergone an external and internal environment, assessment of activity of the organization, besides, the modern and estimated regulatory base defining a way of managing and to use a complex of mathematical and statistical methods, market, market and other researches [16-20].

Today, characterized by instability of economic development, it is possible to state existence of a huge set of the uncountable factors causing risks for which leveling resort to use of various ways. In the context of the last allocation of four groups presented by the methods allowing to realize management concerning risks is expedient. It is about:

1. the method allowing to evade from emergence of risk;

2. the method allowing to localize risk;

3. the method allowing to dissipate risk;

4. the method allowing to compensate risk.

\section{Results}

In our study, we propose to use an integrated approach to managing the risks of an investment and construction project.

Taking a comprehensive approach to risk management, the investor at the exit receives more accurate data on assessing the effectiveness of the investment project, since it is the integrated approach that allows you to identify and investigate the most important risks for investment project, calculate the likely values of economic efficiency indicators (taking into account possible losses) and, as a result, make an optimal investment decision. 
In this work, we propose the following algorithm for integrated risk analysis and assessment (Figure 1).

According to this algorithm, risk assessment begins with a qualitative analysis. At the first stage, it is necessary to identify possible risks of a specific investment project, classify and group them. As a rule, specific risks associated with the implementation of the project at each stage are identified. For convenience, the project is divided into stages and engaged in step-by-step risk assessment. According to practice, the number of risks identified can be huge, especially for complex projects, but on average no more than 30-40 are considered.

\section{Qualitative analysis}

\begin{tabular}{|c|c|c|}
\hline 1. Risk Identification & 2. Risk Classification & 3. Risk Grouping \\
\hline \multicolumn{3}{|c|}{ II. Quantitative analysis } \\
\hline 4. Risk calculation & 5. Risk assessment & $\begin{array}{c}\text { 6. Selection of important } \\
\text { risks }\end{array}$ \\
\hline \multicolumn{3}{|c|}{ III. Scenario Design } \\
\hline 7. Calculation of possible scenarios & 8 . Select the most likely scenario \\
\hline
\end{tabular}

Fig. 1. Comprehensive risk management algorithm

Once the existing risks have been identified, a quantitative analysis should be carried out in which each risk will be calculated and evaluated. At this stage, the most significant risks for the project are selected. The purpose of the quantitative analysis is to identify the most significant risks in terms of their impact on the project's NPVs and predict the likelihood of their occurrence. Having determined the level of risk, you can draw conclusions about the implementation of the project and about possible losses in case of this risk, as well as about the consequences, about steps to eliminate it.

The next step is scenario design. According to this method, it is necessary to consider 3 scenarios, the best, probabilistic and worst. The scripting method is calculated using specialized computer programs. The most accessible tool is a special tool - script manager in MS Excel.

Risk assessment by scenario method is carried out in several steps:

1. Selection of several options for key indicator changes (possible scenarios, e.g. optimistic, probable and pessimistic);

2. Determination of probabilistic assessment for each variant of change (determined by expert method); 
3. Calculation of the value of the performance indicator (NPV, IRR, PI) for each scenario;

4. Analysis of the results.

\section{Discussion}

The application of the above-mentioned methods, which enable to analyze and regulate the risks associated with investment, requires the possession of: a base that includes large information blocks; technologies that enable them to be processed; an impressive amount of theoretical and practical knowledge; highly qualified analytics professionals who are able to think constructively and evaluate in a predictive way. This makes the process aimed at managing the risk category very complex, labour intensive and costly. However, practical experience shows that it is not necessary to neglect the process that allows managing risks, as this may be fraught with the inability to maximize profits and reduce the financial sustainability of persons who are subjects of investment.

\section{Conclusions}

It should be noted that, despite the importance of risk analysis, no method allows you to $100 \%$ say which projects will be effective and profitable [21]. For the most part, much determines the reliability of the expert assessment, so it is very important to find good qualified experts.

In our opinion, only the execution of the work according to the above algorithm of the evaluation methodology will minimize the total damage from risks during the implementation of the investment and construction project.

\section{References}

1. Yu. Ya. Eleneva, V.N. Andreev, Li Zhiyu. Development of an approach to the management of investment projects in industrial enterprises on the basis of risk assessment. Russian Journal of Innovation Economics 9 (2), pp. 489-500 (2019).

2. V.V. Kovalyov. Methods of evaluating investment projects. M: Finance and Statistics (2009).

3. A.A. Vilensky, V.N. Livshits, S.A.Smolyak. Evaluation of the effectiveness of investment projects. Theory and practice. 3rd ed., Approx., Supplement. M.: Case (2012).

4. I.V. Lipsits, V.V. Kosov. Investment project: methods of preparation and analysis. M.: BECK (2012).

5. R.B. Peiser, A.B. Frey. Professional real estate development. ULI Business Guide. M.: UDP (2003).

6. O. Helmer. Social Technology, N.Y. (1966).

7. A. Violante, C. Dominguez, A. Paiva, Risk management in construction projects: are small companies prepared? MOJ Civil Eng. 4(1), pp. 1-7 (2018).

8. P. J. Edwards, P. A. Bowen. Risk and risk management in construction: A review and future directions for research, Engineering Construction and Architectural Management, Vol. 5, No. 4, pp. 339-349 (1998). 
9. R. Flanagan, G. Norman. Risk Management and Consruction. 5 Aufl, Oxford (UK): Blackwall Science (2000).

10. D. Hilson. Project risk management: Future developments, International Journal of Project and Business Risk Management, Vol. 2, No. 2, pp. 1-11, (1998).

11. K. Park, H.W. Lee, K. Choi, et al. Project Risk Factors Facing Construction Management Firms. Int J Civ Eng 17, pp. 305-321 (2019).

12. V.K. Gupta, J.J. Thakkar. A quantitative risk assessment methodology for construction project. Sādhanā 43, p.116 (2018).

13. L. Ustinovichius, G. Shevchenko, D. Kochin, R. Simonaviciene. Classification of the Investment Risk in Construction. In: Luo Y. (eds) Cooperative Design, Visualization, and Engineering. CDVE 2007. Lecture Notes in Computer Science, vol. 4674. Springer, Berlin, Heidelberg (2007).

14. H. Malekitabar, A. Ardeshir, M. H. Sebt, R. Stouffs and E. A. L. Teo. On the calculus of risk in construction projects: contradictory theories and a rationalized approach. Saf. Sci. 101, pp.72-85 (2018).

15. L. Farina, E. Danesi, A. Travaglini, M. Mancini, P. Trucco. Integration of Constructability and Project Risk Management. In: Viles E., Ormazábal M., Lleó A. (eds) Closing the Gap Between Practice and Research in Industrial Engineering. Lecture Notes in Management and Industrial Engineering. Springer, Cham. (2018).

16. E. Amit, B. Dutta, M.J. Kolhatkar. Study of risk management in construction projects. Int J Manag 5(6), pp. 976-6502 (2014).

17. X. Zhao, B.G. Hwang, W. Phng. Construction project risk management in Singapore: Resources, effectiveness, impact, and understanding. KSCE J. Civ. Eng. 18, pp. 27-36 (2014).

18. E. L. Giles, M. Brennan, A. Albogamy, N. Dawood. Development of a client-based risk management methodology for the early design stage of construction processes: applied to the KSA. Eng. Construct. Archittect. Manag. 22, pp. 493-515 (2015).

19. W. Jung, S. H. Han. Which risk management is most crucial for controlling project cost? J. Manag. Eng. 33(5), pp. 22-25 (2017).

20. A.N. Baba Ahmed, A. Megnounif. The impact of risk management on business performance: case of Algerian construction organizations. Innov. Infrastruct. Solut. 5, p. $102(2020)$.

21. B.P.Titarenko, S.M. Lubkin, S.Y. Eroshkin, N.A. Kameneva. Robust and traditional methods of risk management in investment and construction projects. Tenth International Conference Management of Large-Scale System Development (MLSD), IEEE, pp. 1-4. (2017). 